\title{
Persistent left superior vena cava draining into the left atrium
}

\author{
Patrick Tobbia, ${ }^{1}$ Leslie A Norris, ${ }^{2}$ Timothy Lane ${ }^{1}$
}

${ }^{1}$ Department of Internal Medicine, Cone Health, Greensboro, North Carolina, USA

${ }^{2}$ UNC Eshelman School of Pharmacy, Chapel Hill, North Carolina, USA

Correspondence to Dr Patrick Tobbia, tobbia@gmail.com
To cite: Tobbia $P$, Norris LA, Lane T. BMJ Case Rep Published online: [please include Day Month Year] doi:10.1136/bcr-2013010167

\section{SUMMARY}

A 40-year-old man was admitted with necrotising fasciitis of the right thigh. Further workup to evaluate for an infectious source revealed an incidental finding of persistent left superior vena cava via transesophageal echocardiography. This finding was confirmed by cardiac MRI. During his hospitalisation, he also developed altered mental status which was found to be secondary to systemic emboli by a head MRI. The primary source of infection was likely his dental abscesses. He underwent intravenous antibiotic therapy for a total of 6 weeks and was then referred to a specialised vascular centre for further management of his congenital anomaly.

\section{BACKGROUND}

Persistent left superior vena cava (PLSVC) is the most common congenital anomaly of the thoracic venous system, with an incidence of $0.3 \%$. Ninety per cent of PLSVC cases drain into the right atrium (RA), and are largely asymptomatic. Drainage of PLSVC into the left atrium (LA) is uncommon and is likely to be symptomatic. ${ }^{12}$

PLSVC is usually detected incidentally on thoracic imaging modalities or during vascular catheterisation. ${ }^{2} 3$

Though associated with a 10 -fold increase in congenital abnormalities, its sole finding is usually benign unless the PLSVC drains into the LA, causing a systemic right to left shunt which may lead to overwhelming widespread small septic emboli and death. ${ }^{1}$

In this case report, we reviewed the available literature as it pertains to PLSVC and discuss clinical implications of this congenital anomaly.

\section{CASE PRESENTATION}

An otherwise healthy 40-year-old Caucasian man with no significant medical history presented to the emergency department (ED) with a 4-day history of right thigh pain and swelling. Five days prior to his presentation, he experienced a toothache, which subsequently resolved. He endorsed subjective fever and chills 2 days prior to his presentation. The patient underwent a CT scan in ED secondary to his thigh pain that showed necrotising fasciitis deep to the right femur. The patient underwent irrigation and drainage of the area. The patient was admitted with fever and necrotising fasciitis of the right thigh. After admission, the patient was found to have multiple dental abscesses and had a total of seven teeth removed including teeth \#1, \#2, \#4, $\# 5$, \#12, \#15 and \#16. An infectious disease (ID) consult placed the patient on empiric vancomycin, metronidazole and ceftriaxone therapy to cover for presumptive coverage of fastidious aerobic and aanaerobic organisms associated with odontogenic infections. Multiple cultures and gram stains failed to demonstrate the culprit organism for the infection.

As a part of his comprehensive workup, a transesophageal echocardiogram (TEE) was performed to look for the source of infection (figure 1). The TEE showed no valvular vegetations, essentially excluding endocarditis. A bubble study from the left arm showed opacification of the LA and left ventricle, suggestive of a right to left vascular shunt, which was concerning for a vascular abnormality. TEE failed to demonstrate an obvious septal defect or patent foramen ovale (PFO) (video 1).

To further evaluate the TEE bubble study findings, the patient underwent cardiac MRIangiography (MRI/MRA), which demonstrated a PLSVC draining into the LA causing a right to left systemic shunt, thus further explaining the findings from the bubble study (figure 2 and video 2). Left and right ventricular systolic function was normal with an ejection fraction of $54 \%$.

The patient developed altered mental status on hospital day 6 with some tremor and jerking movement that caused concern for seizures. He underwent an EEG, which was within normal limits, with no definite epileptiform features noted. A head MRI/MRA showed four enhancing cortical lesions with vasogenic oedema and central restricted diffusion consistent with small septic emboli. The likely source of infection was the patient's multiple dental abscesses. PLSVC was the cause of systemic emboli in our patient.

\section{INVESTIGATIONS}

Investigations included a TEE to evaluate for a possible source of infection. A bubble study was also performed to assess for an atrial or ventricular septal defect or a vascular anomaly. Cardiac MRI/ MRA was performed to further evaluate the findings of the bubble study.

\section{DIFFERENTIAL DIAGNOSIS}

Possible differential diagnoses include atrial septal defect, ventricular septal defect, PFO and vascular anomalies.

\section{TREATMENT}

Potential treatment strategies include observation or surgical correction of the cardiac shunt. 


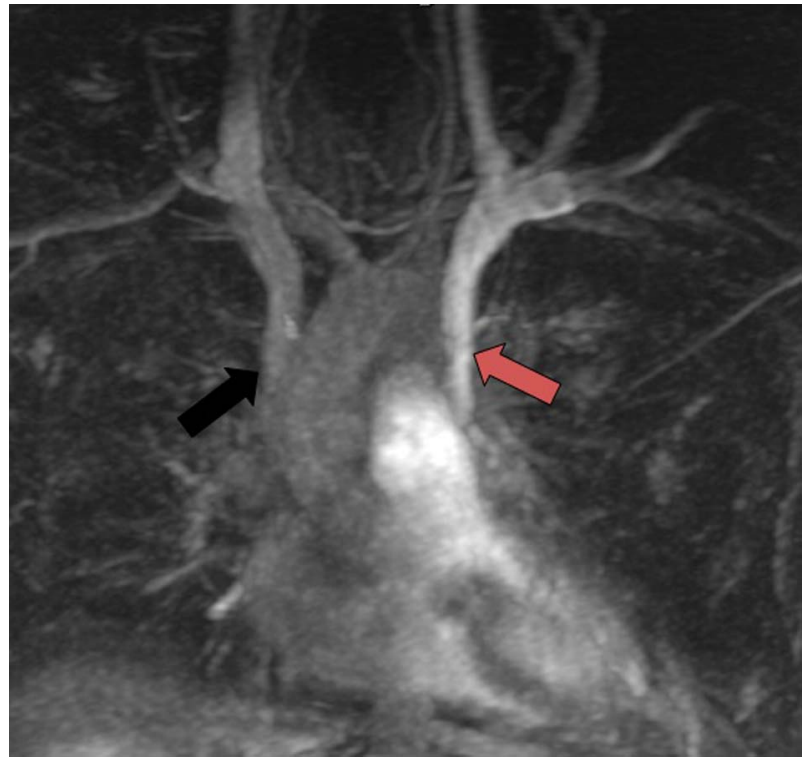

Figure 1 Short axis colour flow of transesophageal echocardiography. No signs of patent foramen ovale detected.

\section{OUTCOME AND FOLLOW-UP}

On discharge, the patient was doing well. A referral to a specialised centre for his congenital vascular defects was established for further evaluation and treatment after he finished a total 6 week course of treatment with ceftriaxone and metronidazole without vancomycin coverage. The patient underwent surgical repair via sternotomy to re-route his PLSVC to the RA 5 months after diagnosis. Following surgery, he completed cardiac rehabilitation. The patient is currently doing well per most recent follow-up.

\section{DISCUSSION}

In order to understand the pathophysiology of PLSVC, it is important to note certain aspects of fetal cardiovascular development. In the fifth week of fetal development, there are three distinct pairs of major veins, including: the vitelline, which carries blood from the yolk sac to the sinus venosus; the umbilical veins, which carry oxygenated blood to the embryo; and the cardinal veins, which drain the body of the embryo. The

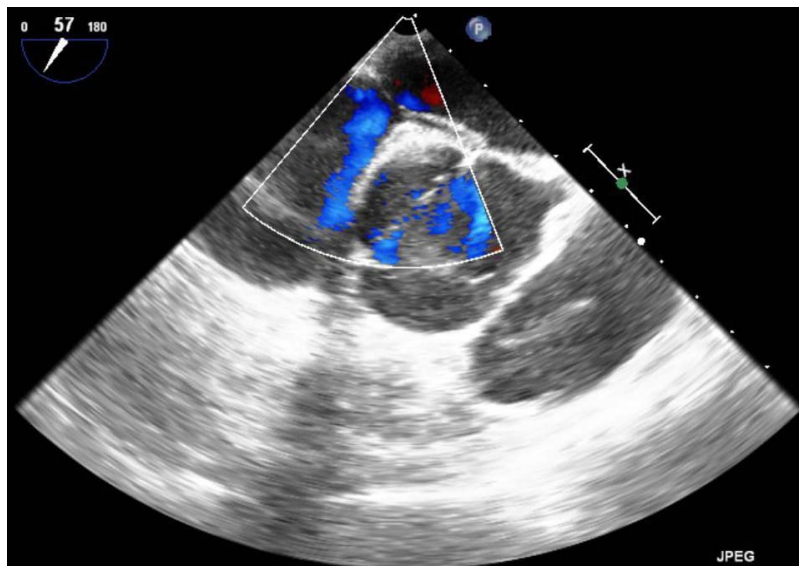

Figure 2 Cardiac MRI demonstrates congenital anomaly with the black arrow pointing at the right superior vena cava (SVC) draining into the right atrium, and the red arrow pointing towards the persistent left SVC draining into the left atrium, which led to the patient's shunt and sequelae of events during his hospitalisation.

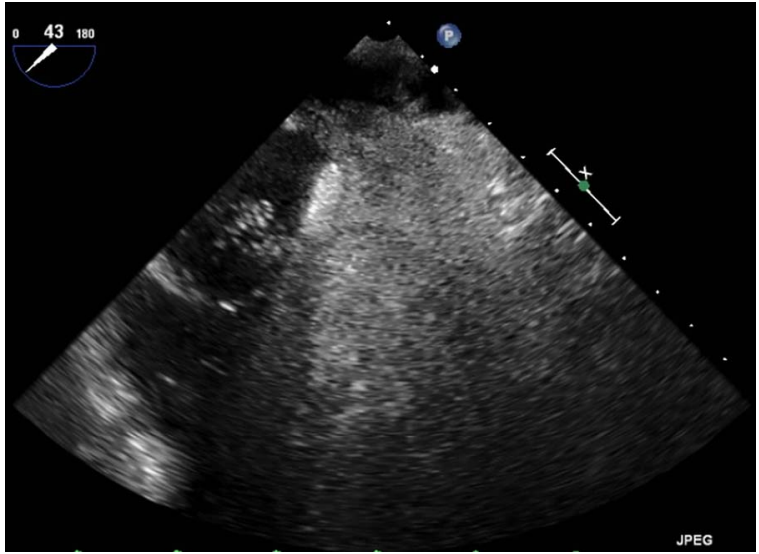

Video 1 Transesophageal echocardiogram bubble study from the left arm showing opacification of the bubbles exclusively in the LA and subsequently LV without evidence of intracardiac shunting suggesting a vascular malformation (normally opacification of the bubbles occurs in the right atrium).

cardinal veins are the main venous drainage system for the embryo originally and consist of the anterior and posterior cardinal veins, which join before entering the sinus horn and form the short common cardinal veins. The vena cava system is formed by anastomoses that develop in the eighth week of gestation and lead to movement of blood from the left to the right side. The left brachiocephalic vein is developed from the anastomosis between the anterior cardinal veins, which leads to blood from the left side of the head and upper extremity to route to the right side. The right common cardinal vein and proximal portion of the right anterior cardinal vein lead to the formation of the superior vena cava. The cause of a PLSVC is persistence of the left anterior cardinal vein and destruction of the common cardinal vein as well as the proximal part of the right anterior cardinal vein. In cases where the PLSVC drains into the left atrium, as in our patient, venous drainage that is intended for the right side of the heart (RA) is re-routed to the left side of the heart (LA). ${ }^{1}$

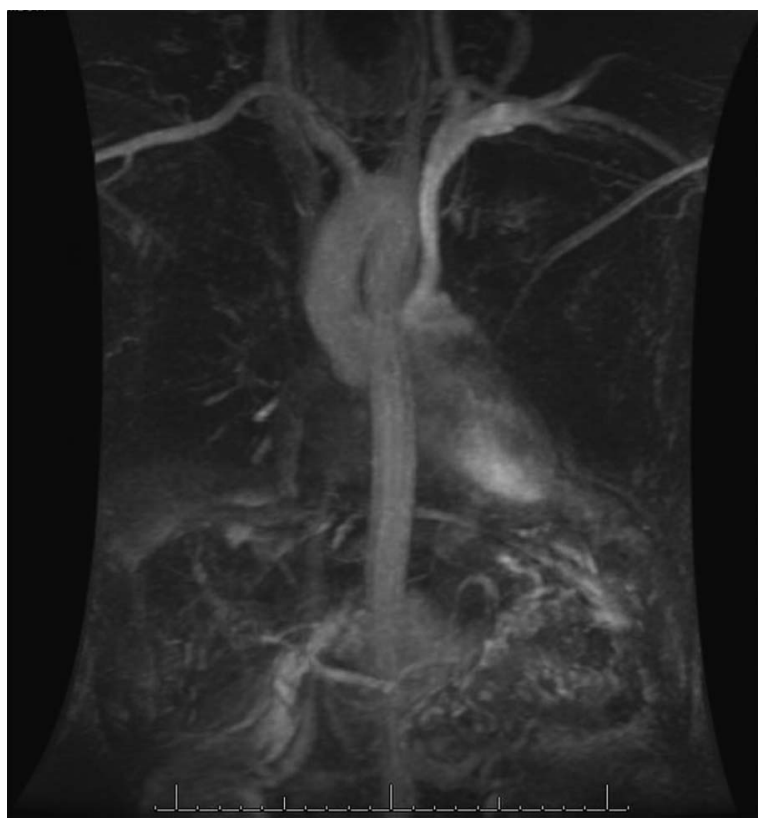

Video 2 Coronal MRA view of the thoracic cavity shows arterial and venous enhancement which demonstrates a PLSVC entering the LA. 
PLSVC is usually diagnosed incidentally during cardiovascular imaging or surgery. ${ }^{2} 3$ This was the case with our patient, who underwent a TEE with bubble study to rule out infective endocarditis as a possible cause for the discomfort he presented.

Owing to the obvious vascular malformation, PLSVC draining into the LA can complicate certain procedures involving access to the left subclavian vein with the intention to reach the right side of the heart, such as right heart catheterisation, Swan-Ganz catheter, permanent pacemaker and implantable cardioverter defibrillator placement. ${ }^{4}$

The type of congenital anomaly determines the haemodynamic effects. Patients with PLSVC draining into the RA usually have no haemodynamic consequences. ${ }^{1}{ }^{2}$ The presence of a PLSVC connecting directly to the LA is uncommon but results in a small right to left shunt, as was seen in our patient. This is associated with an increased risk of cyanosis, heart failure, intracerebral abscess, disseminated infection and embolic cerebrovascular stroke. ${ }^{5-9}$ The lungs serve as a mechanical filter for the blood, and the presence of a right to left shunt can allow entrance of clots or septic particles into the arterial circulation.

PLSVC is generally asymptomatic with little physiological impact, except in patients where the PLSVC drains into the LA

\section{Learning points}

- Persistent left superior vena cava (PLSVC) is a rare condition with an incidence of $0.3 \%$. Of these cases, less than $10 \%$ drain into the left atrium.

- PLSVC should be suspected when a right to left shunt is detected with an imaging modality such as a transesophageal echocardiography. Diagnosis can be confirmed through CT or MRI of the thoracic vasculature.

- PLSVC which drains into the right atrium is largely asymptomatic. Drainage into the left atrium leads to a systemic shunt and is usually symptomatic, leading to potential complications.

- PLSVC draining into the left atrium can complicate certain procedures involving access to the left subclavian vein, such as right heart catheterisation, Swan-Ganz catheter, permanent pacemaker and implantable cardioverter defibrillator placement. causing a large right to left shunt. PLSVC impacts venous procedures, such as central line placement and pacemaker implantation, and must be considered as failure to account for this variant can result in potentially lethal complications. If indicated, the treatment of PLSVC includes surgical correction of the venous abnormality. The guidelines regarding when to treat PLSVC are unclear, however, expert opinion suggests correction in the case of symptomatic hypoxaemia and significant shunting. Examples of treatment options include percutaneous occlusion of the PLSVC or surgical re-routing to the right heart circulation. ${ }^{10-12}$

Contributors All the authors has contributed significantly to the manuscript including (1) substantial contributions drafting the case or revising it critically for important intellectual content and (2) final approval of the version to be published.

Competing interests None.

Patient consent Obtained.

Provenance and peer review Not commissioned; externally peer reviewed.

\section{REFERENCES}

1 Paval J, Nayak S. A persistent left superior vena cava. Singapore Med J 2007;48: e90-3.

2 Biffi M, Boriani G, Frabetti $L$, et al. Left superior vena cava persistence in patients undergoing pacemaker or cardioverter defibrillator implantation: a 10-year experience. Chest 2001;120:139-44.

3 Ratliff $\mathrm{HL}$, Yousufuddin M, Lieving WR, et al. Persistent left superior vena cava: case reports and clinical implications. Int J Cardiol 2006;113:242-6.

4 Goyal SK, Punnam SR, Verma G, et al. Persistent left superior vena cava: a case report and review of literature. Cardiovasc Ultrasound 2008;6:50.

5 Metzler B, Hillebrand $H$, Eulenbruch HP, et al. Persistent left superior vena cava with right-left shunt into the left atrium. Dtsch Med Wochenschr 2002;127:83-6.

6 Kuhn A, Hauser M, Eicken A, et al. Right heart failure due to an unroofed coronary sinus in an adult. Int J Cardiol 2006;113:248-9.

7 Erol I, Cetin II, Alehan F, et al. Brain abscess associated with isolated left superior vena cava draining into the left atrium in the absence of coronary sinus and atrial septal defect. Cardiovasc Intervent Radiol 2006;29:454-6.

8 De Geest B, Vandommele J, Herregods MC, et al. Isolated left sided superior vena cava draining into the left atrium associated with recurring intracerebral abscesses. A case report. Acta Cardiol 1994;49:175-82.

9 Recto MR, Sadlo H, Sobczyk WL. Rare case of persistent left superior vena cava to left upper pulmonary vein: pathway for paradoxical embolization and development of transient ischemic attack and subsequent occlusion with an amplatzer vascular plug. J Invasive Cardiol 2007;19:E313-16.

10 Troost E, Gewillig M, Budts W. Percutaneous closure of a persistent left superior vena cava connected to the left atrium. Int J Cardiol 2006;106:365-6.

11 Geggel RL, Perry SB, Blume ED, et al. Left superior vena cava connection to unroofed coronary sinus associated with positional cyanosis: successful transcatheter treatment using Gianturco-Grifka vascular occlusion device. Catheter Cardiovasc Interv 1999;48:369-73.

12 Takach TJ, Cortelli M, Lonquist JL, et al. Correction of anomalous systemic venous drainage: transposition of left SVC to left PA. Ann Thorac Surg 1997;63:228-30.

Copyright 2013 BMJ Publishing Group. All rights reserved. For permission to reuse any of this content visit

http://group.bmj.com/group/rights-licensing/permissions.

BMJ Case Report Fellows may re-use this article for personal use and teaching without any further permission.

Become a Fellow of BMJ Case Reports today and you can:

- Submit as many cases as you like

- Enjoy fast sympathetic peer review and rapid publication of accepted articles

- Access all the published articles

- Re-use any of the published material for personal use and teaching without further permission

For information on Institutional Fellowships contact consortiasales@bmjgroup.com

Visit casereports.bmj.com for more articles like this and to become a Fellow 